\title{
Effect of Different Acid Components on Multi-Walled Carbon Nanotubes
}

\author{
Ugur Akbaba \\ Kafkas University, Department of Physics Teaching, Kars, Turkey
}

\begin{abstract}
A B S T R AC T
n this study, interactions of multi-walled carbon nanotubes (MWCNTs) samples with Hydrochloric acid $(\mathrm{HCl})$, Nitric acid $\left(\mathrm{HNO}_{3}\right)$, Aqua regia $\left[(\mathrm{AR})=\mathrm{HCl}: \mathrm{HNO}_{3}(3: 1)\right]$ and Reverse aqua regia, $\left[(\mathrm{RAR})=\mathrm{HCl}: \mathrm{HNO}_{3}(1: 3)\right]$ acid and acid mixtures were investigated. Changes in the structure of the samples were analyzed by Fourier transform infrared spectroscopy (FT-IR) and Raman spectroscopy. In addition, the adsorption rates of the acid solutions of the samples were determined. The MWCNTs material has been found to exhibit a high adsorption rate (\%34.70) for the RAR mixture. The same mixture caused the highest defect formation in the structure (\%25). The AR mixture significantly reduced the number of defects in the sample (\%63). According to the purposes of industrial and technological applications, acid and acid mixtures can be used to purify carbon-based structures and to extend the surface area by adding functional groups to the structure.
\end{abstract}

Keywords:

MWCNTs, Defect formation, Adsorption rate, Acid interaction, Purification, Surface extending.

\section{INTRODUCTION}

W ith the discovery of multi-walled carbon nanotubes (MWCNTs), it has become a desirable material in various technological applications. This material is desirable because of its unusual properties. These properties include the desired electrical, physical, optical and mechanical properties, thermal stability, large surface areas, tensile strength, and their ability to be modified according to the purpose [1-4]. Owing to this remarkable properties, MWCNTs and other forms of carbon based materials have a wide range of applications in technological applications. Drug delivery systems, biosensors, transistors, nanocomposites, nanoscale electronic devices, hydrogen storage devices, energy storage devices, compositematerials use MWCNTs and other carbon based materials (Single walled carbon nanotubes (SWCNTs), double walled carbon nanotubes (DWCNTs), graphene, Functionalization Carbon Nanotube (FCNTs), Buckypapers etc.) extensively $[4,5]$. The interaction of MWCNTs with different acid species causes serious modifications on the structure of the material. The changes resulting from this exposure may be beneficial and harmful according to the intended use. This interaction has been used to modify the material for purpose. Different methods such as laser vaporization, electric-arc discharge and chemical vapor deposition are used to produce MWCNTs. Very little of the product obtained in this production process is MWCNTs, the other parts being undesirable nanocrystalline graphite, amorphous carbon, carbonyl structures such as fullerenes and other metals. These unwanted parts are regarded as defects in the structure and may need to be removed from the structure and purification of the structure according to the purpose of application [4]. Many different methods have been developed to remove these unwanted structures. The most common method used for purification is oxidative treatments using strong oxidizing acids [6]. In these acid treatments, $\mathrm{HNO}_{3}, \mathrm{H}_{2} \mathrm{SO}_{4}$, $\mathrm{HCl}$ acids and mixtures of these acids in different ratios were used [7-9]. The effect of acid type, amount and acid mixture ratios applied varies in every carbon based structure. It was determined that amorphous carbon structures in SWCNTs were better removed by applying concentrated $\mathrm{HNO}_{3}$ and $\mathrm{H}_{2} \mathrm{SO}_{4}$ mixtures, while $\mathrm{HCl}$ application was more effective in removing catalytic nanoparticles [10]. Carbon nanotubes tend to achieve thermodynamic stability by forming bonds with many $\Pi-\Pi$ and Van der Waals interactions. Due to this tendency, it is quite difficult to obtain carbon structures having a homogeneous distribution. Many methods such as ultra-sonication, addition of surfactant, chemical modification of nanotube surface are used to disperse these bond struc- 
tures. By adding functional groups to carbon nanotube surfaces, solubility and dispersibility of nanotubes can be improved. This allows the construction of new hybrid materials with liquid-compatible carbon content. One way to add a functional group to the surface is to expose the carbon material to the acid. Nitric acid was used for oxidation of MWCNTs structure. Graphite and metal catalytic structures were removed by gradual purification with a low acid concentration solution. Oxygenated groups were added to the surface of the MWCNTs using more concentrated acid solutions. This gives the opportunity to obtain functionalized materials which can be used in different technological applications [11]. In highly sensitive applications such as the construction of electronic devices, the production of chemical and biological sensors, carbon nanotube with high purity is required. Purification of this material is a highly popular field of research. For example, refluxing of nitric acid is extensively used in the purification of SWCNTs. In this purification process, foreign metals, amorphous carbons, graphite nanoparticles and other imperfections that are in the structure of SWCNTs are eliminated [12]. Observing the changes in the structure of MWCNTs subjected to three different chemical oxidation processes with gave interesting results. In these processes, sonication and refluxing techniques with $\mathrm{H}_{2} \mathrm{SO}_{4} / \mathrm{HNO}_{3}$ acids were applied together and separately. As a result, intensive oxidation was detected in MWCNTs structure which was subjected to acidic sonication for 24 hours. The dimensions of the carbon nanotubes have changed significantly due to the damage occurring to the MWCNTs walls [5]. Another reason why multi-walled carbon nanotubes are preferred in technological applications is that they have a lower cost production process. But due to the van der Waals interactions inherent in this structure, its solubility is very low. This is the biggest obstacle to hybrid applications of the material. The best way to increase solubility is to form functional groups on the structure. By forming carboxylated groups, the modifiable structure is increased. Different functional groups can be introduced to the structure with different acidic treatments [13]. Sulfuric and nitric acid treatment was also applied to modify the surface of MWCNTs according to their intended use. By means of surface modification, the electrical, chemical and optical properties of the structure can be changed in accordance with the purpose. This provides flexibility to use in important technologies such as hydrogen storage and medical applications etc. [14]. When the structural analysis of MWCNTs subjected to nitric and sulfuric acid was done, it was found that after the acid application, the oxygen content increased in the structure and $\mathrm{COOH}$ groups formed on the nanotube surfaces. But these formations did not deform the carbon nanotube lattice. This is an important observation [15].
The ability of carbon-based structures to adsorb acid, other organic chemicals, heavy metals from aqueous solutions, and to store hydrogen is particularly useful for environmental cleaning, wastewater cleaning, and energy storage mechanisms. The toxic adsorption capabilities of carbon nanotubes (CNTs) are important for the environment and human health. Carbon-based structures owe these capabilities due to their large surface area, high reactivity, and unique hollow tube structure. With this motivation, many studies have been conducted especially on the adsorption mechanisms of MWCNTs. As a result of the activation of MWCNTs with different acid species, significant increases in surface areas occur according to the degree of functional group formation. This expansion of the surface area also results in significant yield increases in hydrogen storage applications. In this context, changes in the surface area of the $\mathrm{HCl}, \mathrm{HNO}_{3}, \mathrm{H}_{2} \mathrm{SO}_{4}$ and $\mathrm{HF}$ acids in MWCNTs were investigated and it was found that HF acid significantly increased the surface area of the structure. Other acid types have increased their surface area less than HF acid [1]. It was found that fulvic acid (FA) was adsorbed by SWCNTs better than MWCNTs. The electrostatic, hydrophobic, $\Pi-\Pi$ and hydrogen band interaction mechanisms between FA and CNTs surfaces are the main causes of adsorption $[16,17]$. The adsorption capacity of copper II ions by MWCNTs in the presence and absence of humic and fulvic acid environments was investigated. As a result of the study, it was observed that the presence of these acid environments positively affected the adsorption at $\mathrm{pH}$ values less than 7.5 , but the ionic strength did not contribute to the adsorption process in the wide $\mathrm{pH}$ range. It was concluded that MWCNTs are the materials that can be used to remove heavy metals present in aqueous solutions [18]. MWCNTs modified by polyaluminium chloride in water treatment processes, which is one of the biggest problems of today, have been found to be a very effective material for removing humic acid from aqueous solution [19]. As a result of all interactions that cause adsorption, it is obvious that there are changes in the structure of the material such as defect formation, functional group formation, and defect reduction.

To observe the structural changes in MWCNTs lattice due to interaction acidic solutions with carbon-based structures, Transmission electron microscopy (TEM), thermogravimetric analysis (TGA), Raman spectroscopy, highresolution, transmission electron microscopy (HR-TEM), Fourier transform infrared spectroscopy (FTIR), Field Emission Scanning Electron Microscopy (FE-SEM), Energy dispersive X-Ray spectroscope (EDX), Thermal Gravimetric measurements (TG) are used extensively [5, 12, 15].

Here, the changes in the structure of MWCNTs exposed to $\mathrm{HCl}, \mathrm{HNO}_{3}, \mathrm{HCl}: \mathrm{HNO}_{3}(3: 1)$ and $\mathrm{HCl}: \mathrm{HNO}_{3}(1: 3)$ acid and acid mixtures were determined by FT-IR and Ra- 
man spectroscopy. It was also evaluated how much the material adsorbs these acid species. In particular, the interaction of $\mathrm{HCl}: \mathrm{HNO}_{3}(3: 1)$ and $\mathrm{HCl}: \mathrm{HNO}_{3}(1: 3)$ acid mixtures with MWCNTs has rarely been studied.

\section{MATERIALS AND METHODS}

MWCNTS with the diameter of 10-20 nm, length of 10$30 \mu \mathrm{m}$, and 99\% purity (provided by Grafen Chemical Industries Co., Ltd.) were used in this examination. In different flasks, $30 \mathrm{~mL}$ concentrated $\mathrm{HCl}, \mathrm{HNO}_{3}, \mathrm{HCl}: \mathrm{HNO}_{3}$ (3:1) and $\mathrm{HCl}: \mathrm{HNO}_{3}(1: 3)$ were added to MWCNTs $(0.035$ g). The mixtures was allowed to room temperature for $48 \mathrm{~h}$. The mixture was poured into a pre-weighed Gooch crucible (no 3) to filter. After the filtrations, for obtaining percentage of adsorption, the Gooch crucibles and their contents were dried in room temperature and then weighed. FT-IR spectra were recorded from the solid samples in the range of $4000-600 \mathrm{~cm}^{-1}$ by using a PerkinElmer Frontier FT-IR spectrometer with an ATR diamond accessory. For Raman experiments, a WITec alpha $300 \mathrm{R}$ Micro-Raman spectrometer using a $532 \mathrm{~nm}$ wavelength laser with $0.5 \mathrm{mWatt}$ laser power.

\section{RESULTS AND DISCUSSION}

\section{MWCNTs Adsorption Percentages For Acids And Acids Mixtures}

The percentages of adsorption of $\mathrm{HCl}, \mathrm{HNO}_{3}$, aqua regia (AR) and reverse aqua regia (RAR) on the MWCCNTs were presented in the graph in Fig. 1.

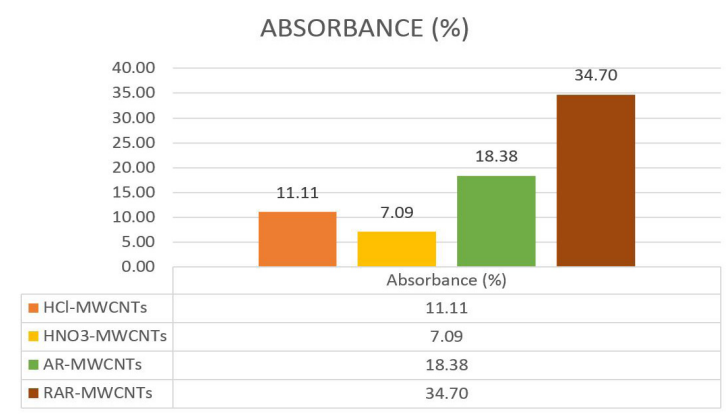

Figure 1. The percentages of adsorption of $\mathrm{HCl}, \mathrm{HNO}_{3}$, aqua regia (AR) and reverse aqua regia (RAR) on the carbon nanotube.

When the adsorption rates in the Fig. 1 are considered, it is seen that the MWCNTs structure absorbs the most RAR acid mixture. The least adsorption rate is seen for HNO3 acid. An interesting result is that MWCNTs absorb the acid mixtures more than the single acid species. Acidic structures are known to be harmful to living organisms. However, acid structures are used extensively in industrial applications. Acid pollution is one of the main factors, especially in the pollution of water resources. In this context, the graph gives remarkable results considering the removal of acid from aqueous media by MWCNTs [19-21].

\section{FT-IR Spectra Results}

FT-IR technique is one of the most effective methods for identifying and naming functional groups formed on carbon-based structures [5, 31]. The FT-IR spectra of MWCNTs, MWCNTs-HCl, MWCNTs- $\mathrm{HNO}_{3}$, MWCNTs-AR (Aqua Regia) and MWCNTs-RAR (Reverse Aqua Regia) were given in Fig. 2.

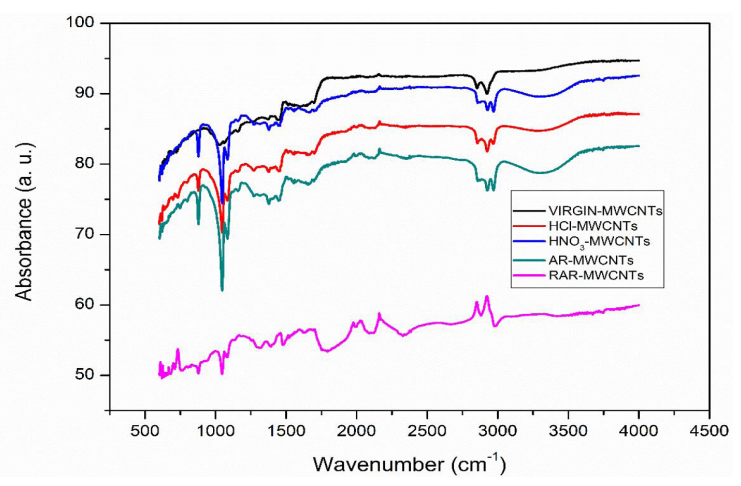

Figure 2. FT-IR Spectra of CNT, CNT-HCl, CNT-HNO, $\mathrm{CNT}-\mathrm{AR}$ and CNT-RAR

The spectra of MWCCNTs-HCl, MWCNTs- $\mathrm{HNO}_{3}$, MWCNTs-AR and MWCNTs-RAR were evaluated by investigated the changes in the vibration modes of the functional groups of the CNT. FT-IR spectra of MWCNTs observed dominant peaks at 1030, 1283, 1328, 1443, 2852 and $2973 \mathrm{~cm}^{-1}$ attribute to $\mathrm{Si}-\mathrm{O}, \mathrm{C}-\mathrm{N}, \mathrm{N}-\mathrm{CH}_{3}, \mathrm{CNT}$, and $\mathrm{C}-\mathrm{H}$ stretching vibrations, respectively [22]. The Si-O vibration bands were showed at $1046 \mathrm{~cm}^{-1}$ for MWCNTs$\mathrm{HCl}, \mathrm{MWCNTs}-\mathrm{HNO}_{3}$, MWCNTs-AR and MWCNTsRAR. The $\mathrm{N}-\mathrm{CH}_{3}$ stretching frequencies for MWCNT-HCl, MWCNTs- $\mathrm{HNO}_{3}, \mathrm{MWCNTs-AR}$ and MWCNTs-RAR were appeared at 1373, 1378, 1378 and $1397 \mathrm{~cm}^{-1}$, respectively. The characteristic vibration band related to MWCNTs displayed at $1454 \mathrm{~cm}^{-1}$ (for MWCNTs- $\mathrm{HCl}$ ), $1454 \mathrm{~cm}^{-1}$ (for MWCNTs- $\mathrm{HNO}_{3}$ ), $1456 \mathrm{~cm}^{-1}$ (for MWCNTs-AR) and 1480 $\mathrm{cm}^{-1}$ (for MWCNTs-RAR). The $\mathrm{C}-\mathrm{H}$ stretching vibrations were observed at 2973 and $2924 \mathrm{~cm}^{-1}$ (for MWCNTs$\mathrm{HCl}$ ), 2970 and $2923 \mathrm{~cm}^{-1}$ (for MWCNTs- $\mathrm{HNO}_{3}$ ), 2926 and $2970 \mathrm{~cm}^{-1}$ (for MWCNTs-AR) and 3010 and $2976 \mathrm{~cm}^{-1}$ (for MWCNTs-RAR). Unlike the vibrations of MWCNTs, the Q-branch for $\mathrm{HCl}$ was showed at $2855 \mathrm{~cm}^{-1}$ (for MWCNTs$\mathrm{HCl}$ ), $2836 \mathrm{~cm}^{-1}$ (for MWCNTs-AR) and $2880 \mathrm{~cm}^{-1}$ (for MWCNTs-RAR) [23, 24]. The broad band in the region 3500-3300 $\mathrm{cm}^{-1}$ in FT-IR spectra of MWCNTs- $\mathrm{HNO}_{3}$, MWCNTs-AR and MWCNTs-RAR was attributed to O-H stretching vibrations of nitric acid. Similarly, the $\mathrm{NO}_{2}$ stretching vibrations of nitric acid were observed at $1688 \mathrm{~cm}^{-1}$ (for MWCNT-HNO ${ }_{3}$ ), 1698 cm$^{-1}$ (for MWCNTs-AR) and 1699 $\mathrm{cm}^{-1}$ (for MWCNTs-RAR) [25]. When the results are examined, the shifts occurring after acid exposure at characteristic peaks indicate that the acid structures penetrate the MWCNTs structure to different sizes and form different functional groups. Again, the significant shift in characte- 
ristic carbon peaks in the sample exposed to the RAR acid mixture is noteworthy. The highest adsorption rate was determined in this mixture.

\section{Raman Results}

Raman spectroscopy is the most widely used reliable technique for characterizing different carbon based structures such as graphite-like and diamond-like [26]. The ratio of the $\mathrm{D}$ band showing the vibrations of the defects and the $\mathrm{G}$ band showing the graphitization (ID/ IG) is the quality parameter of these structures. The low rate means that the better structure quality. Again, the shifts in the formation points of the D, G and $2 \mathrm{D}$ bands are clues indicating the changes in the structure [27]. Fig. 3 presents Raman spectra of virgin MWCNTs sample and MWCNTs samples subjected to various acid and acid mixtures.

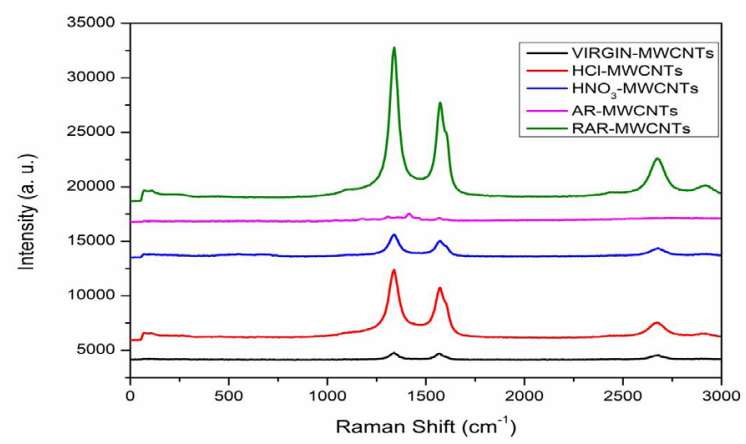

Figure 3. Raman spectra of virgin MWCNTs and MWCNTs subjected to $\mathrm{HCl}, \mathrm{HNO}_{3}, \mathrm{AR}$ and RAR acids solutions.

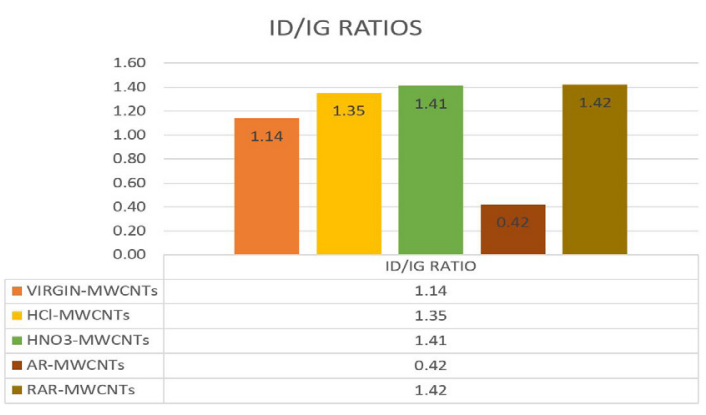

Figure 4. ID/IG ratios obtained from the analysis of Raman spectra.

\section{D/G/2D BAND PEAK POINTS}

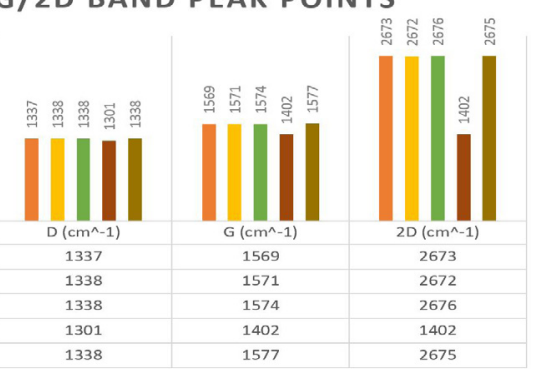

Figure 5. Bands peaks points of virgin and acidified samples.
Raman results (in Figs. 3 and 4) show that the highest defect rate is in the sample subjected to RAR mixture. There has been a $25 \%$ defect increase compared to the virgin sample. On the contrary, the sample exposed to AR mixture shows a significant reduction in defect formation (63\%) compared to the virgin sample. In the samples exposed to $\mathrm{HCl}$ and $\mathrm{HNO}_{3}$ solutions, the defect increase was $18 \%$ and $24 \%$ respectively. Since some industrial and technological applications require high purity MWCNTs, the applicability of the AR mixture in the purification process of MWCNTS should be evaluated. It is also notable that band peaks shifts in the same sample (in Fig. 5). The adsorption rate of the sample (34.70\%) exposed to the RAR mixture is highest (in Fig. 1). The highest adsorption rate and defect formation rate in this sample are compatible results. The structure of MWCNTs is believed to be suitable for removing the mixture in an environment where the RAR mixture is present. There are also visible differences in the FI-TR graph (in Fig. 2) of the sample that has been subjected to the RAR sample compared to the other samples graphs. This shows that the structure adsorbs this solution intensely and new functional groups are formed as a result of adsorption. When other adsorption rates are examined, it is seen that this structure absorbs acid mixtures better than pure acid contents. These results can be taken into account for environmental health and water treatment.

\section{CONCLUSION}

In this study, MWCNTs were exposed to $\mathrm{HCl}, \mathrm{HNO}_{3}$, $\mathrm{HCl}: \mathrm{HNO}_{3}$ (3: 1, aqua regia, AR) and $\mathrm{HCl}: \mathrm{HNO}_{3}(1: 3$, reverse aqua regia, RAR) acids and acid mixtures. Changes in MWCNTs structure were investigated by FT-IR, Raman spectroscopy techniques. In addition, its reaction to the solutions was examined with adsorption rates. MWCNTs samples were determined to adsorb AR and RAR acid mixtures better than single acid type. The highest adsorption was obtained for RAR solution. When FT-IR spectra are considered, the most intense functional group formation occurs in the RAR mixture. Raman analysis shows that the most intense defect formation occurs within this sample. In terms of purification, the AR mixture was found to be very suitable with a $63 \%$ defect reduction. The shifts in FT-IR and Raman peaks show that the material reacts more with the acid mixtures rather than the single acid type. The electrostatic, hydrophobic hydrogen and $\Pi-\Pi$ coactions, which are the cause of these interactions, are indicative of the interaction densities between the structure and acid mixtures. The results obtained should be taken into account in the purification of MWCNTs and in the expansion of the surface area by forming functional groups. The results can be examined in more detail for the hydrogen storage process and additional investigations can be made. Adsorption capabilities according to acid types can be considered for 
waste treatment and environmental health.

\section{ACKNOWLEDGEMENT}

This study was supported by the scientific research project unit of Kafkas University in Turkey under the project number (2016-FM-71).

\section{REFERENCES}

1. Reyhani A, Mortazavi SZ, Golikand AN, Moshfegh AZ, Mirershadi, S. The effect of various acids treatment on the purification and electrochemical hydrogen storage of multi-walled carbon nanotubes. Journal of Power Sources, 183 (2) (2008) 539-543.

2. Špitalský Z, Aggelopoulos C, Tsoukleri G, Tsakiroglou C, Parthenios J, Georga S, Krontiras C, Tasis D, Papagelis K, Galiotis C. The effect of oxidation treatment on the properties of multi-walled carbon nanotube thin films. Materials Science and Engineering: B 165(3) (2009) 135-138.

3. Saleh TA. The influence of treatment temperature on the acidity of MWCNT oxidized by $\mathrm{HNO} 3$ or a mixture of $\mathrm{HNO} 3 / \mathrm{H} 2 \mathrm{SO} 4$. Applied Surface Science 257(17) (2011) 7746-7751.

4. Kruusenberg I, Alexeyeva N, Tammeveski K, Kozlova J, Matisen L, Sammelselg V, Gulo'n JS, Feliu JM. Effect of purification of carbon nanotubes on their electrocatalytic properties for oxygen reduction in acid solution. Carbon 49(12) (2011) 4031-4039.

5. Maciejewska BM, Jasiurkowska DM, Vasylenko AI, Kozioł KK, Jurga S. Experimental and theoretical studies on the mechanism for chemical oxidation of multiwalled carbon nanotubes. RSC Advances 4(55) (2014) 28826-28831.

6. MacKenzie K, Dunens O, Harris AT. A review of carbon nanotube purification by microwave assisted acid digestion. Separation and Purification Technology 66(2) (2009) 209-222.

7. Pumera M, Šmíd B, Veltruská K. Influence of nitric acid treatment of carbon nanotubes on their physico-chemical properties. Journal of Nanoscience and Nanotechnology 9(4) (2009) 2671-2676.

8. Shen L, Liu M. A New Purification Way for Multi-walled Carbon Nanotubes. In Applied Mechanics and Materials (Trans Tech Publications) 457 (2014) 240-243.

9. Pillai SK, Ray SS, Moodley M. Purification of multi-walled carbon nanotubes. Journal of nanoscience and nanotechnology, 8(12) (2008) 6187-6207.

10. Chiang IW, Brinson BE, Huang AY, Willis PA, Bronikowski MJ, Margrave JL, Smalley RE, Hauge RH. Purification and characterization of single-wall carbon nanotubes (SWNTs) obtained from the gas-phase decomposition of $\mathrm{CO}$ (HiPco process). The Journal of Physical Chemistry B 105(35) (2001) 8297-8301.

11. Yudianti R, Onggo H, Saito Y, Iwata T, Azuma JI. Analysis of functional group sited on multi-wall carbon nanotube surface. The Open Materials Science Journal 5(1) (2011)
12. $\mathrm{Hu} \mathrm{H}$, Zhao B, Itkis ME, Haddon RC. Nitric acid purification of single-walled carbon nanotubes. The Journal of Physical Chemistry B 107(50) (2003) 13838-13842.

13. Lee GW, Kim J, Yoon J, Bae J S, Shin BC, Kim IS, Oh Weontae, Ree M. Structural characterization of carboxylated multi-walled carbon nanotubes. Thin Solid Films, 516(17) (2008) 5781-5784.

14. Turgunov MA, Oh JO, Yoon SH. Surface modification of multiwall carbon nanotubes by sulfuric acid and nitric acid. Materials 64 (2014) 22-25.

15. Le TMH. Characterization of multi-walled carbon nanotubes functionalized by a mixture of $\mathrm{HNO} / \mathrm{H} 2 \mathrm{SO} 4$. Diamond and Related Materials 89 (2018) 43-51.

16. Yang K, Xing B. Adsorption of fulvic acid by carbon nanotubes from water. Environmental Pollution 157(4) (2009) 1095-1100.

17. Pan B, Xing B. Adsorption mechanisms of organic chemicals on carbon nanotubes. Environmental Science \& Technology 42(24) (2008) 9005-9013.

18. Sheng G, Li J, Shao D, Hu J, Chen C, Chen Y, Wang X. Adsorption of copper (II) on multi-walled carbon nanotubes in the absence and presence of humic or fulvic acids. Journal of Hazardous Materials 178(1-3) (2010) 333-340.

19. Li S, Li Z, Ke B, He Z, Cui Y, Pan Z, Li D, Su J, Lai C, Su J. Magnetic multi-walled carbon nanotubes modified with polyaluminium chloride for removal of humic acid from aqueous solution. Journal of Molecular Liquids 279 (2019) 241-250.

20. Liesivuori J, Savolainen AH. Methanol and formic acid toxicity: biochemical mechanisms. Pharmacology \& Toxicology 69(3) (1991) 157-163.

21. Kudo N, Kawashima Y. Toxicity and toxic-kinetics of perfluorooctanoic acid in humans and animals. The Journal of Toxicological Sciences 28(2) (2003) 49-57.

22. Misra A, Tyagi PK, Rai P, Misra DS. FTIR Spectroscopy of multiwalled carbon nanotubes: a Simple approach to study the nitrogen doping. Journal of nanoscience and nanotechnology 7(6) (2007) 1820-1823.

23. Perez J, Velasco S, White JA, Hernández AC. Infrared spectra of $\mathrm{HCl}, \mathrm{HBr}$ and $\mathrm{HI}$ dissolved in liquid xenon. Journal of Molecular Liquids 45(1-2) (1990) 71-76.

24. Lehman JH, Terrones M, Mansfield E, Hurst KE, Meunier V. Evaluating the characteristics of multiwall carbon nanotubes. Carbon 49(8) (2011) 2581-2602.

25. Robert MS, Francis XW, David JK. Spectrometric identification of organic compounds. seventh ed. John wiley \& Sons, Inc, Hoboken, (106) 2005.

26. Antunes EF, Lobo AO, Corat EJ, Airoldi VJT, Martin AA, Veríssimo C. Comparative study of first-and second-order Raman spectra of MWCNT at visible and infrared laser excitation. Carbon 44(11) (2006) 2202-2211.

27. Akbaba U, Kasapoğlu AE, Gür E. Gamma and neutron irradiation effects on multi-walled carbon nanotubes. Diamond and Related Materials 87 (2018) 242-247. 